\title{
Alergia en la práctica clínica
}

\author{
Allergy in clinical practice
}

El 4 de Septiembre de 2015 se realizaron en Santiago, las Segundas Jornadas de Primavera de la Sociedad Chilena de Enfermedades Respiratorias tituladas "Alergia Clínica Práctica". El programa contó con la participación de dieciséis prestigiosos docentes nacionales en temas tan contingentes como asma bronquial, rinitis alérgica, aeroalergenos, infecciones virales y su relación con alergias, reacciones adversas a fármacos e infecciones recurrentes en niños y adultos entre otras interesantes materias.

Esta vez las actividades de las jornadas se realizaron concentradas en un solo día a fin de facilitar la asistencia de los profesionales interesados, lo que pensamos fue bien acogido. Contamos con 99 inscritos de los cuales el $80 \%$ fueron médicos.

Las enfermedades alérgicas son patologías muy frecuentes que afectan a los pacientes en las fases de sus vidas en las que la producción laboral o académica es más intensa. Interfieren de forma significativa en las actividades cotidianas y frecuentemente perturban el sueño. Las consecuencias socioeconómicas de todos estos aspectos son muy importantes y muy superiores a las que hace sólo unas cuantas décadas se les atribuía.

La tendencia al crecimiento paulatino en la frecuencia de las enfermedades alérgicas ha sido una constante en las últimas cuatro o cinco décadas, con cierta tendencia al estancamiento en los últimos años, aunque sólo en los países desarrollados. Este fenómeno se ha hecho especialmente patente en los procesos mejor estudiados, como la dermatitis atópica, la rinitis alérgica y el asma bronquial.

La OMS ha llegado a clasificar las enfermedades alérgicas entre las seis patologías más frecuentes del mundo. Se estima que pueden afectar al 20\% de la población mundial, y resultan más afectados los países desarrollados e industrializados que el resto. En nuestro medio, se calcula que una de cada cuatro personas puede padecer de algún tipo de trastorno alérgico a lo largo de su vida.

Todas estas circunstancias han despertado la inquietud de los investigadores y han motivado que las publicaciones cientificas relacionadas con enfermedades alérgicas se hayan multiplicado de forma espectacular en las últimas décadas, situándose al nivel de las relacionadas con patologías cardiovasculares o neurológicas. Estos hechos tampoco han dejado indiferentes a los medios de comunicación, que se hacen eco reiteradamente de la preocupación de los médicos, de los pacientes y de las autoridades sanitarias por estas patologías.

Por otra parte, el aumento del consumo de fármacos en la población junto a la mayor expectativa de vida ha ocasionado que las reacciones adversas a fármacos sean cada día más frecuentes en la práctica clínica. En servicios de Alergología se aprecia un aumento sostenido en el número de consultas por alergia a medicamentos, llegando a ser el tercer motivo de consulta (15\%). Destacados docentes revisaron los mecanismos fisiopatológicos de este tipo de reacciones, sus manifestaciones clínicas, elementos diagnósticos y protocolos de desensibilización.

Los médicos que tratan pacientes con infecciones respiratorias recurrentes a menudo enfrentan el dilema de dilucidar si se trata de un proceso de tipo alérgico, de inmunodeficiencia o de ambos. La combinación de una inmunodeficiencia primaria y alergia puede estar presente en pacientes con infecciones recurrentes. Un aspecto importante a tener presente es que las inmunodeficiencias primarias no sólo se presentan en la infancia sino que también pueden manifestarse por primera vez en la edad adulta. Los pacientes con inmunodeficiencias primarias tienen mayor riesgo de desarrollar infecciones, alergias, enfermedades autoinmunes y neoplasias. Un adecuado control de los síntomas 
alérgicos disminuye la frecuencia de infecciones bacterianas, pero esto no es así cuando el paciente cursa además con una inmunodeficiencia la cual deberá ser manejada en forma conjunta con la alergia. En estas jornadas, médicos nacionales de gran experiencia se refirieron al enfrentamiento de niños y adultos con infecciones respiratorias recurrentes, aftas orales recurrentes y la utilidad de los fármacos inmunoestimulantes disponibles en nuestro medio.

Agradecemos sinceramente la generosa y destacada participación de todos los docentes invitados que con sus excelentes presentaciones dieron realce a esta iniciativa de nuestra sociedad.

Dras. Rosa María Feijóo Seoane y María Evelyn Chala Calvo Coordinadoras Segundas Jornadas de Alergia Clínica Práctica 2015

Sociedad Chilena de Enfermedades Respiratorias

Email:rmfeijoo@gmail.com 